\title{
Atrial and Brain Natriuretic Peptides Stimulate the Production and Secretion of C-Type Natriuretic Peptide From Bovine Aortic Endothelial Cells
}

\author{
Brunilda Nazario, ${ }^{\star}$ Ren-Ming Hu, ${ }^{\star}$ Ali Pedram, ${ }^{*}$ Bruce Prins, ${ }^{\ddagger}$ and Ellis R. Levin *‡ \\ Division of Endocrinology, Veteran Affairs Medical Center, Long Beach, Long Beach, California 90822; and Departments of *Medicine \\ and ${ }^{\ddagger}$ Pharmacology, University of California, Irvine, Irvine, California 92717
}

\begin{abstract}
C-type natriuretic peptide (CNP) is a member of the natriuretic peptide family which is produced in vascular endothelial cells and may play an important paracrine role in the vasaculature. We sought to determine the regulation of CNP production by other vasoactive peptides from cultured aortic endothelial cells. The vasoconstrictors endothelin-1 and angiotensin II had little effect on the basal secretion of CNP. In contrast, atrial natriuretic peptide (ANP) and brain natriuretic peptide (BNP) strongly stimulated the secretion of CNP. BNP caused as much as a 400 -fold enhancement above the basal accumulated secretion of CNP over $24 \mathrm{~h}$ at a concentration of $1 \mu \mathrm{M}$; this was 20 times greater than the stimulatory effect of ANP. BNP and ANP also significantly enhanced the production of new CNP protein (translation) and mRNA expressed in the BAEC. In contrast, C-ANP-423, a truncated form of ANP which selectively binds to the natriuretic peptide clearance receptor, did not stimulate CNP secretion. The enhanced production and secretion of CNP, caused by either ANP or BNP, was significantly prevented by LY 83583, an inhibitor of cGMP generation, and was also attenuated by $\mathrm{KT}$ 5823, an inhibitor of cGMPdependent protein kinase. Our results indicate that ANP and BNP can stimulate CNP production through a guanylate cyclase receptor on endothelial cells. BNP is a much more potent stimulator of CNP secretion, compared to ANP. Our findings suggest that the vasodilatory, and anti-mitogenic effects of ANP and BNP in the vasculature could occur in part through CNP production and subsequent action if these interactions occur in vivo. (J. Clin. Invest. 1995. 95:1151-1157.) Key words: translation - guanylate cyclase - protein kinase
\end{abstract}

\section{Introduction}

The natriuretic peptide family (1) is comprised of three proteins, each derived from a separate gene. Atrial natriuretic peptide $(\mathrm{ANP})^{1}$ (2) and brain natriuretic peptide (BNP) (3) circu-

Address correspondence to Ellis R Levin M.D., Medical Service (111I), Long Beach Veterans Hospital, $5901 \mathrm{E}$ 7th St., Long Beach, CA 90822. Phone: 310-494-2611 x5748; FAX: 310-494-5675.

Received for publication 29 June 1994 and in revised form 7 November 1994.

1. Abbreviations used in this paper: Ang, angiotensin II; ANP, atrial natriuretic peptide; BAEC, bovine aortic endothelial cell cultures; BNP, brain natriuretic peptide; CNP, C-type natriuretic peptide; ET-1, endothelin-1; GC, guanylate cyclase; VSMC, vascular smooth muscle cell.

The Journal of Clinical Investigation, Inc.

Volume 95, March 1995, 1151-1157 late in plasma after secretion from the heart in adult humans. The third family member, C-type natriuretic peptide (CNP), was originally described in the central nervous system, where it is found in much greater concentrations than either ANP or BNP (4). CNP is derived after processing from a prepro hormone of 126 amino acids, and a pro-hormone of 53 amino acids (5). Recently, CNP has been found to be produced in endothelial cells, where its secretion can be regulated by cytokines and growth factors $(6,7)$.

CNP has insignificant natriuretic and diuretic properties compared to ANP (4). CNP acts as a venodilator and a vasodepressor in the $\operatorname{dog}(4,8,9)$ and inhibits vascular smooth muscle cell (VSMC) proliferation in vitro $(10,11)$. After binding to both the natriuretic peptide guanylate cyclase B (GC-B) and clearance receptors on VSMC (12), CNP could potentially modulate local vasomotor tone or influence the in vivo proliferation of vascular smooth muscle, though there is no direct evidence for this at present. Identifying the vascular factors that regulate CNP production or action might lead to a better understanding of the dynamic events that occur in the vasculature.

The interaction of CNP with important vasoactive peptides is essentially unknown. In these studies, we examined the effects of the other members of the natriuretic peptide family on CNP production and secretion, and compared these to the actions of the vasoconstrictor peptides endothelin-1 (ET-1) and angiotensin II (Ang). We found that ANP and BNP strongly stimulated the production and secretion of CNP, with BNP being much more potent. In contrast, ET-1 and ANG had little effect on CNP secretion. We also determined the type of natriuretic peptide receptor which mediated these actions of ANP and BNP, and established the signaling mechanism involved.

\section{Methods}

Endothelial cell cultures and experiments. Bovine aortic endothelial cell cultures (BAEC) were prepared as previously described $(13,14)$. The BAEC were seeded at a density of 77,000 cells $/ \mathrm{cm}^{2}$ on $100 \mathrm{~mm}$ or 6-well culture plates, passaged once, and cultured in DME with $10 \%$ FBS, then used for experiments $\sim 1$ wk after cell preparation. The cells displayed the typical morphologic characteristics of endothelial cells and virtually all cells showed positive fluorescence with an antibody to factor VIII. The cultures were devoid of any cells having the appearance of smooth muscle cells.

For experiments, subconfluent BAEC were incubated in DME media without serum for various times (time course) up to $24 \mathrm{~h}$, or in the presence of different concentrations $(1-1,000 \mathrm{nM})$ of ANP or BNP, ET-1, or Ang II. In other experiments, either LY $83583\left(10^{-7} \mathrm{M}\right)$ (inhibitor of guanylate cyclase activation) or KT $5823\left(5 \times 10^{-8} \mathrm{M}\right)$ (inhibitor of cGMP-dependent protein kinase) (Calbiochem Corp., San Diego, CA) was added to the BAEC for $30 \mathrm{~min}$ before the natriuretic peptide, or by itself. The media was aspirated and frozen for subsequent radio immunoassay of CNP, and the RNA was extracted from both control (no peptides) and the various experimental plates (4 per condition) as previously described (14). The degradation of ANP and BNP was also compared after $0,4,8$, and $24 \mathrm{~h}$ of exposure to the BAEC. 
This was accomplished by calculating the area under the curves of the ANP or BNP specific peaks, seen after injecting the natriuretic peptidecontaining cell culture medium onto a $\mathrm{C}_{18}$ reverse phase, high pressure liquid chromatography column. The samples were eluted over $30 \mathrm{~min}-$ utes using a $10-40 \%$ acetonitrile: $0.1 \%$ trifluroacetic acid gradient.

CNP radio immunoassay. CNP immunoreactivity was measured by a sensitive double antibody, non-equilibrium assay, using antibody obtained from Peninsula Laboratories (Belmont, CA). The sensitivity of the assay was $1.5-2 \mathrm{pg} /$ tube and the intra and interassay coefficients of variation were always less than $10 \%$. The antibody recognizes CNP22 (rat, porcine, and human CNP-22 are identical) and CNP-53 (ProCNP) but is not reported to cross react with ANP or BNP. We found a cross-reactivity for these latter two peptides $(1 \mu \mathrm{M})$ with CNP of less than $0.0001 \%$ in the RIA.

In vivo translation studies. BAEC were cultured for $7 \mathrm{~d}$, then incubated in methionine-free DME medium with dialyzed 10\% FBS for 1 $\mathrm{h}$ before experimentation $(13,14)$. The cells were then incubated with $250 \mu \mathrm{Ci}$ of $\left[{ }^{35} \mathrm{~S}\right]$ methionine in the presence or absence of ANP or BNP, $100 \mathrm{nM}$, or LY 83583, $100 \mathrm{nM}$, or peptide plus LY 83583, for $8 \mathrm{~h}$. The media was aspirated and saved, and the cells were then washed and lysed in lysis buffer for $1 \mathrm{~h}$ at $4^{\circ} \mathrm{C}(13,14)$. The lysate and secretion media were then precleared and specific labeled CNP protein was immunoprecipitated using polyclonal antibody to CNP. Antibody which was preabsorbed with $\mathrm{CNP}, 10^{-7} \mathrm{M}$, for $12 \mathrm{~h}$ before the immunoprecipitation procedure served as a specificity control. The immunoprecipitated protein was then solubilized in SDS-sample buffer (containing fresh $\alpha$ mercaptoethanol as a reducing agent), and heated to $100^{\circ} \mathrm{C}$ for $5 \mathrm{~min}$. The labeled protein was then electrophoretically resolved on a $4 \%$ stacking/10\% spacing/ $16.5 \%$ separating polyacrylamide gel using a tricine buffer system (cell secretion media) or $12 \%$ separating gel using a glycine buffer system (intracellular lysate). For comparison, molecular weight markers were resolved under the same circumstances. The gel was then stained and destained, and subjected to flurography, then autoradiography for 4-7 d. Each translation experiment was performed at least 3 times. To determine if the intracellular CNP precursor protein was extensively glycosylated, immunoprecipitated and labeled protein from control cells was denatured, then incubated with $0.4 \mathrm{U}$ of $\mathrm{N}$ Glycosidase F, $2 \mathrm{mU}$ Neuraminidase and $2.5 \mathrm{mU}$ o-Glycosidase (Boehringer Mannheim, Indianapolis, IN) for $20 \mathrm{~h}$. The proteins were then separated in parallel and compared to non-deglycosylated proteins on SDS-PAGE as described.

S1 nuclease protection. The extracted RNA was hybridized with a $\mathrm{P}^{32}$-labeled cRNA probe, made from a template of a human cDNA for CNP (5) (kindly provided by Dr Gordon Porter, Scios-Nova, Mountain View, CA). The cDNA was in EcoR1-EcoR1 orientation in pSK and anti-sense and sense cRNA probes were promoted using $T_{7}$ and $T_{3}$ RNA polymerase, respectively. The cRNA probe spans exon 2 of the human CNP gene, and a transcript of approximately 237 bases was protected. Hybridization, S1 nuclease digestion and electrophoretic separation were carried out as previously described $(13,14)$. A HindIII-digested and $\mathrm{P}^{32}$-labeled cRNA for H-ras served as an RNA loading standardization probe. The gel was opposed to film with intensifying screens for $24 \mathrm{~h}$, and the autoradiographic bands were compared by laser densitometry (LKB). Sense probes produced no hybridization.

Statistics. Data from secretion studies were combined $(n=8-12$ wells/condition) and then analyzed by calculating a mean and standard error for each treatment or group. Data from the different conditions were compared by analysis of variance; a multiple range test (Scheffe's) was used for significant $\mathrm{F}$ values $(P<0.05)$. Secretion studies were carried out at least three times. RNA comparisons were quantified by laser densitometry of autoradiographs and data was normalized for RNA loading by creating a ratio of the density of the experimental RNA hybridized with the CNP probe, divided by the same amount of RNA hybridized with $\mathrm{H}$-ras. A ratio was then established by comparing normalized experimental RNA to normalized control RNA which was extracted from non-treated endothelial cells. A value of 1 was arbitrarily assigned to the control. This resulted in values expressing the relative densities of the experimental conditions compared to the control. Protein bands from the translation studies were also compared by laser densitometry.

\section{Results}

CNP secretion. Over time, ANP, $100 \mathrm{nM}$, caused a maximal, 6.3-fold stimulation of CNP secretion from the cultured BAEC (Fig. $1 \mathrm{~A}$ ). The stimulation was significant at $2 \mathrm{~h}$ of incubation and increased to the highest concentration after $24 \mathrm{~h}$ (mean 24 $\mathrm{h}$ basal CNP secretion, 64.8 \pm 5.8 (SEM) pg/ml, mean ANPstimulated CNP secretion $410 \pm 24 \mathrm{pg} / \mathrm{ml}, n=10$ wells $/$ condition, $P<0.05$ ). The accumulated secretion of CNP stimulated by $100 \mathrm{nM}$ BNP was significantly greater than ANP at the same concentration and time points. BNP caused a maximal 13-fold increase above basal secretion at this concentration after $24 \mathrm{~h}$ of incubation (mean BNP-stimulated CNP secretion 849 \pm 65 $\mathrm{pg} / \mathrm{ml}$ ) (Fig. $1 A$ ). In contrast, neither ET-1 nor Ang II, at concentrations as high as $1 \mu \mathrm{M}$, affected the basal secretion of CNP over $24 \mathrm{~h}$ (data not shown). Both ANP and BNP caused a dose-related stimulation of CNP secretion, and again BNP significantly stimulated more CNP secretion, including at a concentration of $10 \mathrm{nM}$ (Fig. $1 \mathrm{~B}$ ). Over several concentrations, BNP was at least one log order of magnitude more potent than ANP in stimulating CNP. We then examined the possibility that the more potent stimulation by BNP, compared with ANP, resulted from there being less degradation of BNP over the 24 $h$ period of exposure to the cells. We found that the exogenously added peptides were comparably degraded at 4, 8, and $24 \mathrm{~h}$; for instance, ANP and BNP were degraded by $\sim 67 \%$ at $24 \mathrm{~h}$.

We also determined that the stimulation of CNP secretion by either ANP or BNP occurred through a guanylate cyclase receptor. This conclusion was reached based upon the fact that C-ANP 4-23, a specific agonist for the natriuretic peptide clearance receptor at the concentrations used in this study $(13,15)$, had no effect on CNP secretion (Fig. $1 B$ ). Furthermore, LY 83583 , an inhibitor of natriuretic peptide-induced guanylate cyclase activation $(13,16)$, prevented either ANP or BNP from stimulating CNP secretion over $24 \mathrm{~h}$ by approximately 100 and $71 \%$, respectively (Fig. 2 ). To provide further understanding of the signaling mechanism involved in the action of the natriuretic peptides, we also studied the effects of KT 5823, an inhibitor of cGMP-dependent protein kinase (17) at the concentration used in this study. We found that KT significantly reversed ANP and BNP-stimulated CNP secretion by 63 and 69\%, respectively, (Table I) $(P<0.05)$.

Translation studies. We next wanted to provide evidence that ANP and BNP regulate CNP production as well as secretion. We therefore metabolically labeled the BAEC, and assessed new CNP protein synthesis (translation) in response to the natriuretic peptides. We also hoped to gain some insight as to the intracellular, precursor forms of CNP found within the cell, or the processed forms secreted into the media, since this type of data has not been described previously. First, we separated proteins (which were secreted into the incubation medium) by SDS-PAGE. We observed two prominent protein bands in the secretion media which corresponded in size to CNP-22 and CNP-53 (Fig. $3 \mathrm{~A}$ ). Thus, both forms are secreted from the cultured cells. This indicates that processing from the high molecular weight, prepro CNP takes place entirely within the cell, giving rise to pro CNP-53: the proCNP is then partially processed within the cell or at the cell membrane, leading to the secretion of CNP-22, since our secretion media contains no serum/processing proteases. Within the cell lysate, we detected 


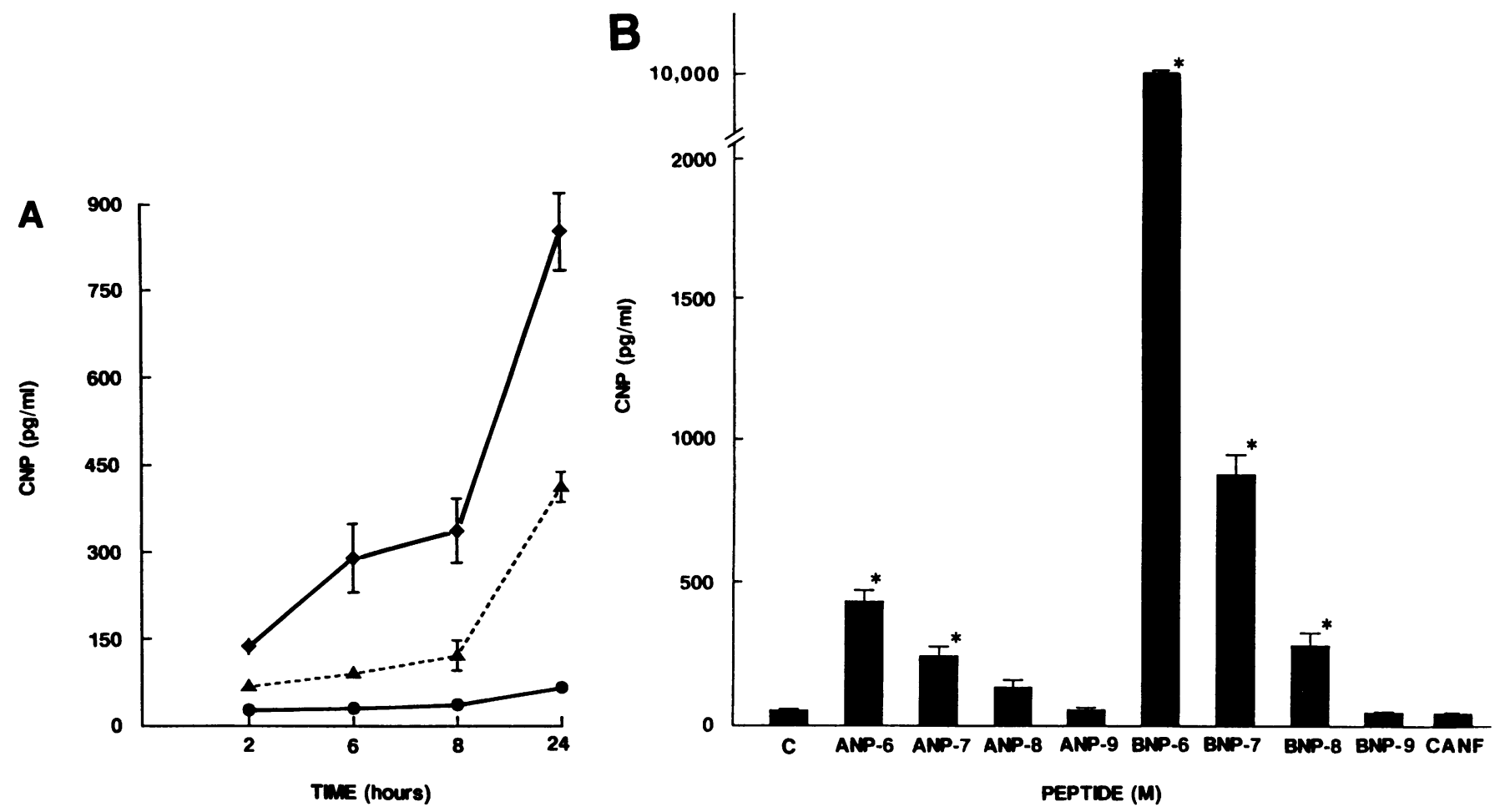

Figure 1. (A) Effect of ANP or BNP, $100 \mathrm{nM}$, on the secretion of CNP from cultured bovine aortic endothelial cells over time. Data are the mean \pm SEM from three experiments combined $(n=10$ wells/condition $) .(\bullet-\bullet)$ is control (absence of peptide) secretion, $(\Delta---\Delta)$ is ANP, $(-\bullet)$ is BNP. Error bars are not shown when the SEM is less than $5 \mathrm{pg} / \mathrm{ml}$. Comparison of control to ANP or BNP-induced CNP secretion is different at all time points $(P<0.05)$ by ANOVA plus Schefe's test. Additionally BNP is significantly different than ANP at 6,8 , and $24 \mathrm{~h}$. (B) Dose-related stimulation of ANP or BNP on CNP secretion at $24 \mathrm{~h}$. Each bar represents the mean \pm SEM from three experiments combined $\left(\mathrm{n}=12\right.$ wells/condition). ${ }^{*} P<0.05$ by ANOVA plus Scheffe's test compared to control. BNP-stimulated CNP secretion is significantly greater than ANP-stimulated CNP $(P<0.05)$ at $10^{-6}$ through $10^{-8} \mathrm{M}$.

a predominant high molecular weight form of CNP, at $\sim 28$ $\mathrm{kD}$ (Fig. $3 \mathrm{~B}$ ). This was found despite treating the cell extract with freshly made reducing agent (2-mercaptoethanol) and SDS, agents which should prevent dimerization or aggregation, including with another intracellular protein. This isoform is substantially larger than the size of the prepro CNP $(\sim 13 \mathrm{kD})$, and we considered it likely to be glycosylated CNP precursor protein. No CNP-53 or CNP-22 was detected in the cell lysate. When we deglycosylated the control, immunoprecipitated protein, it did not change its migration, indicating that the unexpected mobility and size of the precursor protein on SDS-PAGE is not due to extensive glycosylation. We also separated the intracellular protein using both 12 and $16.5 \%$ acrylamide gels, and tricine and glycine buffer systems, but the protein ran very similarly under both conditions.

Importantly, we found that in the cell lysate, ANP and BNP each strongly stimulated the production of new CNP protein. Based on densitometry of the protein bands from four experiments combined, ANP maximally stimulated the production of the high molecular weight forms by $2.94 \pm 0.4$-fold, compared with control. BNP was more potent, stimulating CNP production by $4.78 \pm 0.3$-fold at $100 \mathrm{nM}$ peptide. This was found to be dose-related, and was mediated through binding to a GC receptor, since LY 83583 very significantly blocked the stimulation of CNP production by either natriuretic peptide, while having no significant effect itself. The protein bands were identified as being specifically related to CNP, since antibody which was preabsorbed with CNP immunoprecipitated significantly less protein (Fig. $3 \mathrm{~B}$, lane 9). ANP and BNP, $100 \mathrm{nM}$, also stimulated the ultimate production of CNP-53 and CNP-22 which was secreted into the culture medium, by approximately $3.14 \pm 0.3$ and $4.19 \pm 0.4$-fold, respectively (Fig. $3 A$ ). This probably resulted from the comparable stimulation of precursor protein production. Again, LY 83583 substantially inhibited the stimulated translation of CNP, caused by either ANP or BNP.

$m R N A$ studies. The regulation of the CNP gene by ANP and BNP was then determined by protection assay (Fig. $4 A$ ). First, we found that over time, ANP or BNP, $10^{-7} \mathrm{M}$, each produced a significant increase in CNP steady state mRNA levels of at least 2-3-fold compared to control. This was first noted by $2 \mathrm{~h}$, and extended over the 24-h experimental period. The stimulation was also concentration dependent (Fig. $4 \mathrm{~B}$ ). Based upon combining results from two studies, and normalizing for RNA loading, ANP stimulated CNP gene expression $3.05,1.87$, and 1.3 -fold at $10^{-6}, 10^{-8}$, or $10^{-9} \mathrm{M}$, respectively. BNP induced a stronger 4.04, 2.90, and 1.91-fold increase in CNP mRNA at the same concentrations. Therefore, the stimulated increase in CNP mRNA expression in response to ANP or BNP is consistent with the enhanced production of CNP protein caused by these natriuretic peptides.

\section{Discussion}

CNP is a vasodilator in some species and an inhibitor of vascular smooth muscle proliferation in vitro (11) and probably in vivo (10), acting in paracrine and perhaps endocrine fashion after 

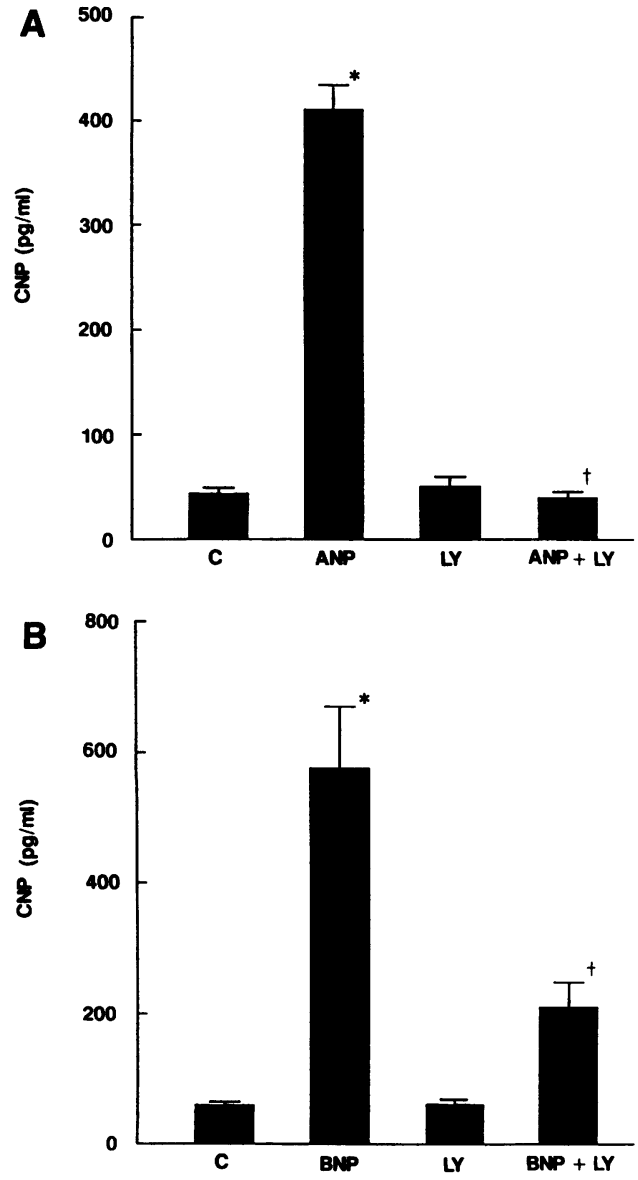

Figure 2. Effects of LY 83583 on the secretion of CNP, stimulated by $100 \mathrm{nM}$ ANP or BNP, from BAEC. Data are the mean \pm SEM from two experiments combined ( $n=7$ wells/condition), and are representative of a third experiment. ${ }^{*} P<0.05$ for ANP or BNP versus control. ${ }^{+} P$ $<0.05$ for ANP or BNP versus the natriuretic peptide plus LY 83583 .

synthesis and secretion from the endothelial cell (6). Hence, the regulation of CNP production and secretion by other vasoactive peptides is potentially important. Here, we report that ANP and BNP strongly stimulate the production and secretion of CNP from cultured aortic endothelial cells, albeit at relatively high concentrations of peptide. BNP is much more potent than ANP

Table I. Effects of KT 5823 on the ANP or BNP-stimulated Production of CNP Over 24 h from Cultured Endothelial Cells

\begin{tabular}{lc}
\hline & CNP \\
\hline Control & $p g / m l$ \\
ANP 100 nM & $25 \pm 1$ \\
BNP 100 NM & $313 \pm 8.2^{*}$ \\
KT 5823 50 nM & $651 \pm 17^{*}$ \\
ANP + KT 5823 & $30 \pm 2.7$ \\
BNP + KT 5823 & $105 \pm 4.8^{\ddagger}$ \\
& $184 \pm 36^{\ddagger}$ \\
\hline
\end{tabular}

Each value is the mean \pm SEM of data from two separate experiments combined ( $n=9-12$ wells/condition), results representative of a third study. $* P<0.05$ by ANOVA plus Scheffe's test for condition versus control. ${ }^{\ddagger} P<0.05$ for ANP or BNP versus ANP or BNP plus KT.

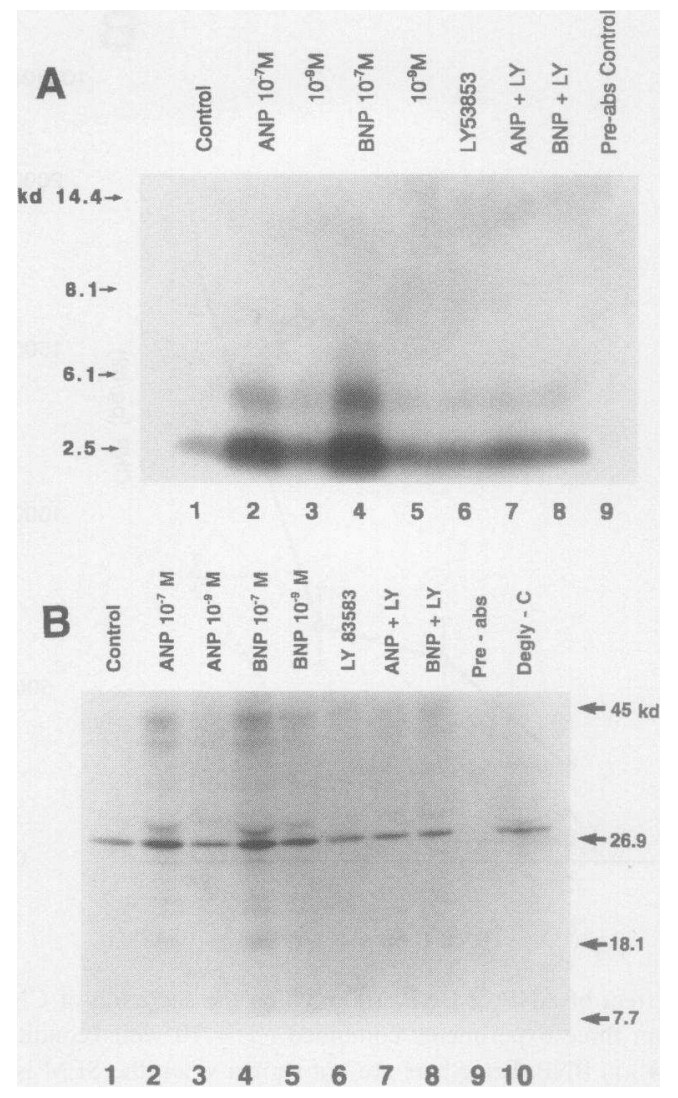

Figure 3. Stimulation of CNP translation by ANP or BNP. Cultured BAEC were incubated with $250 \mu \mathrm{Ci}$ of $\left[{ }^{35} \mathrm{~S}\right]$ methionine in the absence (control) or presence of a natriuretic peptide, 100 or $1 \mathrm{nM}$, or LY83583, $100 \mathrm{nM}$, or both substances. The media was then saved and the cells were lysed, pre-cleared and ET-1 related protein was immunoprecipitated with polyclonal antibody to ET-1. Labeled protein was then separated by SDS-PAGE on a $16.5 \%$ separating gel, using a tricine buffer system (cell secretion media) or $12 \%$ separating gel using a glycine buffer system (intracellular lysate). Molecular weight markers resolved under the same conditions are noted. ( $A$ ) Lanes $1-9$ represent cell incubation media from control BAEC, and cells incubated with ANP ( 100 or $1 \mathrm{nM}$ ), BNP ( 100 or $1 \mathrm{nM}$ ), LY 83583, ANP or BNP, 100 $\mathrm{nM}$, plus LY 83583, or control cell lysate immunoprecipitated with preabsorbed antibody, respectively. The two bands are compatible with pre-pro CNP-53 and CNP-22, respectively. (B) Lanes $1-10$ represent cell lysate from BAEC subjected to the same experimental conditions, except that lane 10 represents control protein that was subjected to deglycosylation. The experiments were repeated an additional two-three times, and autoradiography was performed each time. The density values or comparisons in the text are derived from the mean \pm SEM from the three-four experiments combined.

in these regards, causing as much as a 20 -fold greater stimulation of CNP secretion. ANP and BNP also stimulate increased CNP gene expression, and significantly enhance the formation of new CNP protein (translation) in the cultured BAEC, both of the precursor and fully processed forms. For both these functions, BNP is more potent. The magnitude stimulation of the secretion of CNP over time in response to ANP or BNP does not precisely correlate with the magnitude stimulation of mRNA expression or protein production. However, the stimulated secretion of CNP in our studies represents accumulated secretion into the culture medium over as much as $24 \mathrm{~h}$, on a background of increased production. Increased CNP secretion over time is 


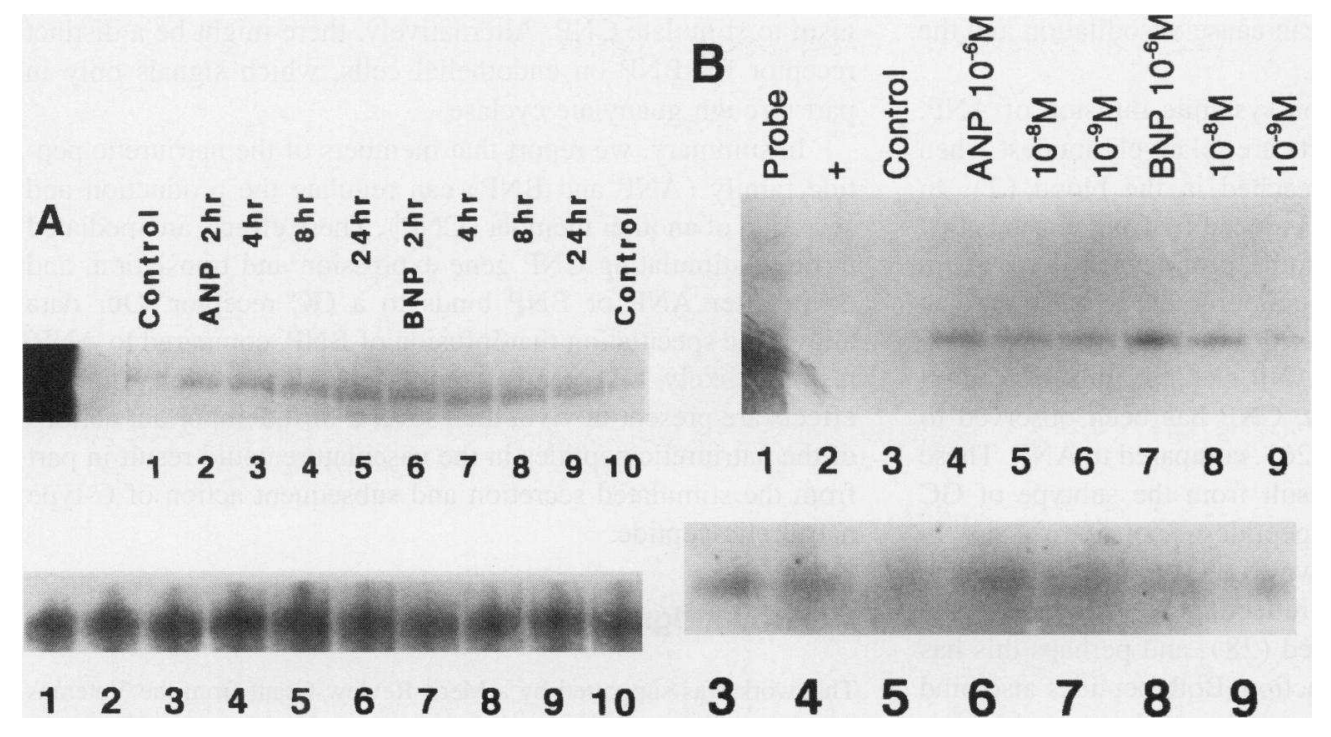

Figure 4. (A) Steady-state CNP mRNA levels from cells incubated with ANP or BNP over $24 \mathrm{~h}$, determined by $\mathrm{S} 1$ nuclease protection. Lanes $1-5$ are the signal from the hybridization of $20 \mu \mathrm{g}$ of total RNA extracted from control BAEC (no peptide), and cells incubated with $100 \mathrm{nM}$ ANP (lanes 2-5), or BNP (lanes 6-9), respectively. Lane 10 is a second control, at $8 \mathrm{~h}$ of incubation. The two lanes to the left of lane $l$ are, respectively, the labeled cRNA probe alone and the probe digested with $\mathrm{S} 1$ nuclease, in the absence of RNA. The lower panel of $A$ is the same amount of RNA from each experimental condition, hybridized with a cRNA probe for $\mathrm{H}$-ras as an RNA loading control. The figures shown are representative of three separate experiments. $(B)$ Dose-response effects of ANP or BNP on CNP mRNA. BAEC were incubated in the absence or presence of ANP or BNP, $10^{-6}, 10^{-8}$, or $10^{-9} \mathrm{M}$ each, for $8 \mathrm{~h}$. Values in the text represent the mean stimulation of CNP by ANP or BNP, derived from two experiments combined, representative of a third study. Corresponding H-ras is seen underneath.

also seen at a lower level in the medium from control cells, where there is no significant change in mRNA expression. Furthermore, there is often a lack of a strict stoichiometric relation between secretion and production of peptide hormones.

These actions of ANP and BNP are mediated through guanylate cyclase (GC) receptors expressed on the endothelial cells, since a specific ligand for the natriuretic peptide clearance receptor has no effect on CNP production/secretion. Furthermore, their effects on both CNP production and secretion occur through the generation of cGMP and the activation of cGMPdependent protein kinase. This is based upon the reversal of the stimulated CNP production/secretion by Ly 83583 and KT 5823 , inhibitors of cGMP production and related-kinase activation, respectively. Finally, the effects of ANP and BNP are specific, since ET-1 and Ang II have no significant effect on CNP secretion.

We found a predominant high molecular weight form of CNP in the labeled endothelial cells, but neither CNP-53 nor CNP-22 was found. The protein was not significantly glycosylated according to our findings, but we cannot rule out another form of post-translational modification. Large molecular weight forms of CNP have been detected by other investigators using gel permeation chromatography in immunoprecipitated lysates from the kidney (18). It has been proposed that the high molecular weight forms may represent a non-specific interaction between CNP antibody and other large proteins (18). This is unlikely however, because when we use antibody which is saturated with CNP before our immunoprecipitation of material from the labeled BAEC, virtually no bands are seen, indicating the specific nature of the interaction of the antibody with newly formed CNP precursor protein. To explain the aberrant behavior on SDS-PAGE, we suggest that the high molecular weight form is specifically linked to another protein which is resistant to mercaptoethanol or SDS, or that the prepro CNP is modified post-translationally other than by the addition of sugar moieties (phosphorylated, farnestlyated, etc.). Since CNP-53 and CNP22 are not found in the cell lysate, this suggests that the prohormone is rapidly processed and secreted. Consistent with our findings, recent studies from Hagiwara et al. indicate that CNP is rapidly secreted and not stored after cell synthesis (19). In the cell medium, both CNP-53 and CNP-22 were found. To date, only CNP-22 has been reported in human plasma $(20,21)$. Therefore, plasma enzymes may play a role in the processing of the pro CNP-53 to CNP-22, although the endothelial cell can also participate in posttranslational modifications/processing, as we determined.

Our results suggest that some of the previously observed effects of ANP ( and BNP) in the vasculature could be explained by the stimulation of the secretion, and subsequent action of CNP. For instance, it is known that ANP can inhibit the proliferation of VSMC, and that this effect is probably mediated through the stimulation of cGMP (reviewed in reference 22). Therefore, we postulate that if in vivo, ANP acts as a growth inhibitor of VSMC through the generation of cGMP, this may be mediated in part through the stimulated release and subsequent action of CNP on smooth muscle cells. Porter et al. (11) recently showed that the anti-proliferative action of CNP greatly exceeds that of ANP for VSMC in culture. Furuya et al. (10) showed that in vivo, the initimal hyperplasia of rat carotid arteries induced by air-drying injury could be substantially suppressed by CNP infusion. Furthermore, TGF- $\beta 1$ can inhibit the proliferation of VSMC and TGF- $\beta$ has been observed to strongly stimulate CNP production from cultured endothelial cells (6). Therefore, it is possible that in vivo, ANP or TGF- $\beta$ might stimulate CNP secretion form the endothelial cell, which could contribute to the anti-mtiogenic action on neighboring smooth muscle cells. However, in vitro results may not be readily extrapolatable to the in vivo situation, since it has been shown that the GC receptor subtype expressed on the in situ aorta is different from that expressed on cultured cells (23). CNP binds to the GC-B subtype of guanylate cyclase receptor, while ANP binds to the GC-A subtype (24). The subtype of GC receptor on a cell may therefore limit the response to CNP if the GC-B receptor is not expressed. Another function for ANP (and CNP) has been to inhibit the secretion of the vasoconstrictor and VSMC mitogen, ET-1 (13, 25). Inhibiting ET-1 provides a common mechanism 
whereby the natriuretic peptides can cause vasodilation and the inhibition of VSMC proliferation.

It has been observed that upon systemic infusion of ANP, the blood pressure lowering effects are relatively modest when physiologic concentrations are reached in the blood (2). In some species, the vasodepression induced by CNP exceeds that of ANP and probably reflects a more pronounced decrease in cardiac output resulting from venodilation and reduced cardiac filling pressure $(9,10,26)$. This differential effect has also been observed after infusion of ANP or CNP into the central nervous system (27). In contrast, CNP has been observed to have weak natriuretic properties (26), compared to ANP. These differential actions may again result from the subtype of GC receptor expressed in natriuretic peptide responsive tissues. In some studies, CNP has been shown to more potently stimulate cGMP when compared to ANP, reflecting the presence of the GC-B receptor in the tissue studied (28), and perhaps this has a role in the different potency of action. Both peptides also bind the $\mathrm{C}$ receptor, but evidence to date indicates that most biological actions of CNP are mediated through the GC-B receptor (19).

Our results indicate that the regulation of CNP by ANP and BNP is mediated through the GC class of receptors. This is based upon our finding that ( $a$ ) C-ANP 4-23, a specific ligand for the natriuretic peptide clearance receptor, has no effect on CNP secretion, and $(b)$ inhibitors of cGMP generation or its related kinase completely reverse the stimulation of CNP production and secretion caused by either ANP or BNP. Other actions of ANP, for instance, the in vitro inhibition of endothelin production and secretion, are mediated through the clearance receptor (13). Both receptors are expressed on endothelial cells (21), in vitro and in vivo, and therefore, both classes of receptors could potentially mediate the overall biological effects of ANP and probably those of BNP. However, most presently defined in vivo actions of ANP appear to be mediated through the $\mathrm{GC}$ receptor.

ANP and BNP bind to the same receptors with roughly equal affinity (12), and to date, have been found to have essentially the same actions and similar potencies on a wide variety of vascular (29) and nonvascular functions (30). Thus, a fundamental question in the field is, what are the relative roles and particularly the unique functions for BNP, compared with ANP? To date, this question is unanswered. Our results indicate that BNP (compared to ANP) is much more potent in its ability to stimulate CNP production and secretion. Therefore, it would be important to know whether BNP acts similarly in vivo, because it may become therapeutically useful to preferably administer this peptide in order to stimulate CNP production in certain cardiovascular disorders. It is unclear as to what is the precise mechanism by which BNP more potently stimulates CNP, compared with ANP. In most studies (including our own unpublished observations) these two peptides stimulate cGMP generation equipotently from endothelial cells (12). However, we observed here that the inhibitor of cGMP generation, LY 83583, completely prevented ANP-induced CNP secretion, while it inhibited BNP-induced CNP 30\% less potently. KT 5823 reversed ANP or BNP-stimulated secretion roughly equally, but neither was complete. The latter finding is consistent with the observation that the relatively selective action of KT for cGMPdependent protein kinase (PKG) at this concentration does not fully inhibit PKG activity. Our results lead us to hypothesize that BNP may act through the guanylate cyclase receptor, but may additionally activate a second, non-cGMP related mecha- nism to stimulate CNP. Alternatively, there might be a distinct receptor for BNP on endothelial cells, which signals only in part through guanylate cyclase.

In summary, we report that members of the natriuretic peptide family (ANP and BNP) can regulate the production and secretion of another member (CNP). These effects are mediated through stimulating CNP gene expression and translation, and occur after ANP or BNP binds to a GC receptor. Our data allows the speculation that infusion of BNP, compared to ANP, is more likely to potently stimulate CNP secretion. If these effects are present in vivo, then several of the important actions of the natriuretic peptides in the vasculature could result in part from the stimulated secretion and subsequent action of C-type natriuretic peptide.

\section{Acknowledgments}

This work was supported by a Merit Review Grant from the Veterans Administration, and National Institutes of Health grant HL-50161 (E. R. Levin). Bruce Prins was supported by a research Fellowship from the American Heart Association, California Affiliate. Brunilda Nazario received a 1994 Merck Senior Fellow Award for this work, presented at the 76th Annual Meeting of the Endocrine Society, Anaheim, CA., June 15-18, 1994, abstr no. 1528.

\section{References}

1. DeBold, A. J., H. B. Borenstein, A. T. Veress, and H. Sonnenberg. 1981. A rapid and potent natriuretic response to intravenous injection of atrial myocardial extracts in rats. Life Sci. 28:89-94.

2. Kangawa, K., and H. Matsuo. 1984. Purification and complete amino acid sequence of $\alpha$-human atrial natriuretic polypeptide ( $\alpha$-hANP). Biochem. Biophys. Res. Commun. 118:131-139.

3. Sudoh, T., K. Kangawa, N. Minamino, and H. Matsuo. 1988. A new natriuretic peptide in porcine brain. Nature (Lond.). 332:78-81.

4. Sudoh, T., N. Minamino, K. Kangawa, and H. Matsuo. 1990. C-type natriuretic peptide (CNP): a new member of natriuretic peptide family identified in porcine brain. Biochem. Biophys. Res. Commun. 168(2):863-870.

5. Tawaragi, Y., K. Fuchimura, S. Tanaka, N. Minamino, K. Kangawa, and H. Matsuo. 1991. Gene and precursor structures of human C-type natriuretic peptide. Biochem. Biophys. Res. Commun. 175(2):645-651.

6. Suga, S-i., K. Nakao, H. Itoh, Y. Komatsu, Y. Ogawa, N. Hama, and H. Imura. 1992. Endothelial production of C-type natriuretic peptide and its marked augmentation by transforming growth factor- $\beta$. J. Clin. Invest. 90:1145-1149.

7. Suga, S-i., H. Itoh, Y. Komatsu, Y. Ogawa, N. Hama, T. Yoshimasa, and K. Nakao. 1993. Cytokine-induced C-type natriuretic peptide (CNP) secretion from vascular endothelial cells-evidence for CNP as a novel autocrine/paracrine regulator from endothelial cells. Endocrinology. 133(6):3038-3041.

8. Wei, C-M., L. Aarhus, V. M. Miller, and J. C. Burnett. 1993. Action of Ctype natriuretic peptide in isolated canine arteries and veins. Am. J. Physiol. 264:H71-H73.

9. Stingo, A. J., A. L. Clavell, L. L. Aarhus, and J. C. Burnett. 1992. Cardiovascular and renal actions of C-type natriuretic peptide. Am. J. Physiol. 262:H308H312.

10. Furuya, M., K. Aisaka, T. Miyazaki, N. Honbou, K. Kawishima, T. Ohno, S. Tanaka, N. Minamino, K. Kangawa, and H. Matsuo. 1993. C-type natriuretic peptide inhibits intimal thickening after vascular injury. Biochem. Biophys. Res. Commun. 193(1):248-253.

11. Porter, J. G., R. Catalano, G. McEnroe, J. A. Lewicki, and A. A. Protter. 1992. C-type natriuretic peptide inhibits growth factor-dependent DNA synthesis in smooth muscle cells. Am. J. Physiol. 263:C1001-C1006.

12. Suga, S-i., K. Nakao, K. Hosoda, M. Mukoyama, Y. Ogawa, G. Shirakami, H. Arai, Y. Saito, Y. Kambayashi, K. Inouye, and H. Imura. 1992. Receptor selectivity of natriuretic peptide family, atrial natriuretic peptide, brain natriuretic peptide, and C-type natriuretic peptide. Endocrinology. 130(1):229-239.

13. Hu, R.-M., E. R. Levin, A. Pedram, and H. J. L. Frank. 1992. Atrial natriuretic peptide inhibits the translation and secretion of endothelin from cultured bovine aortic endothelial cells: Mediation through $\mathrm{C}$ receptors. J. Biol. Chem. 267(24):17384-17389.

14. Hu, R.-M., Chuang, E. Prins, B. Kashyup, M. Frank, H. J. L. Pedram, A., and Levin, E. R. 1994. High density lipoproteins stimulate the production and secretion of endothelin-1 from cultured bovine aortic endothelial cells. J. Clin. Invest. 93:1056-1062.

15. Maack, T., M. Suzuki, F. A. Almeida, D. Nussenzveig, R. M. Scarborough, 
G. A. McEnroe, and J. A. Lewicki. 1987. Physiological role of silent receptors of atrial natriuretic factor. Science (Wash. DC). 238:675-678.

16. O'Donnell, M. E., and N. E. Owen. 1986. Role of cyclic GMP in atrial natriuretic factor stimulation of $\mathrm{Na}^{+}, \mathrm{K}^{+}, \mathrm{Cl}^{-}$cotransport in vascular smooth muscle cells. J. Biol. Chem. 261:15461-15466.

17. Kase, H., K. Iwahashi, S. Nakanishi, Y. Matsuda, K. Yamada, M. Takahashi, C. Murakata, A. Sato, and M. Kaneko. 1987. K-252 compounds, novel and potent inhibitors of protein kinase $\mathrm{C}$ and cyclic nucleotide-dependent protein kinases. Biochem. Biophys. Res. Commun. 142:436-440.

18. Suzuki, E., Y. Hirata, H. Hayakawa, M. Omata, M. Kojima, K. Kangawa, N. Minamino, and H. Matsuo. 1993. Evidence for C-type natriuretic peptide production in the rat kidney. Biochem. Biophys. Res. Commun. 192(2):532-538.

19. Hagiwara, H., S. Hajime, M. Itakura, T. Yoshimoto, M. Furuya, S. Tanaka, and S. Hirose. 1994. Autocrine regulation of rat chondrocyte proliferation by natriuretic peptide $\mathrm{C}$ and its receptor, natriuretic peptide receptor-B. J. Biol. Chem. 269(14):10729-10733.

20. Hama, N., H. Itoh, G. Shirakami, Suga, S-i., Y. Komatsu, T. Yoshimasa, I. Tanaka, K. Mori, and K. Nakao. 1994. Detection of C-type natriuretic peptide in human circulation and marked increase of plasma CNP level in septic shock patients. Biochem. Biophys. Res. Commun. 198(3):1177-1182.

21. Stingo, A. J., A. L. Clavell, D. M. Heublein, C-M. Wei, M. R. Pittelkow, and J. C. Burnett. 1992. Presence of C-type natriuretic peptide in human endothelial cells and plasma. Am. J. Physiol. 263:H1318-H1321.

22. Appel, R. G. Growth-regulatory properties of atrial natriuretic factor. 1992. Am. J. Physiol. 262:F911-F918.

23. Suga, S-i., K. Nakao, I. Kishimoto, K. Hosoda, M. Mukoyama, H. Arai, G. Shirakami, Y. Ogawa, Y. Komatsu, O. Nakagawa, N. Hama, and H. Imura.
1992. Phenotype-related alteration in expression of natriuretic peptide receptors in aortic smooth muscle cells. Circ. Res. 71:34-39.

24. Wong, S. K.-F., and D. L. Garbers. 1992. Receptor guanylyl cyclases. J. Clin. Invest. 90:299-305.

25. Kohno, M., T. Horio, K. Yokokawa, N. Kurihara, and T. Takeda. 1992. Ctype natriuretic peptide inhibits thrombin-and angiotensin II-stimulated endothelin release via cyclic guanosine $3^{\prime}, 5^{\prime}$-monophosphate. Hypertension. 19:320-325.

26. Clavell, A. L., A. J. Stingo, C-M. Wei, D. M. Heublein, and J. C. Burnett. 1993. C-type natriuretic peptide: a selective cardiovascular peptide. Am. J. Physiol. 264:R290-R295.

27. Charles, C. J., A. M. Richards, and E. A. Espiner. 1992. Central C-type natriuretic peptide but not atrial natriuretic factor lowers blood pressure and adrenocortical secretion in normal conscious sheep. Endocrinology. 131(4): $1721-1726$.

28. Furuya, M., M. Takehisa, Y. Minamitake, Y. Kitajima, Y. Hayashi, N. Ohnuma, T. Ishihara, N. Minamino, K. Kangawa, and H. Matsuo. 1990. Novel natriuretic peptide, CNP, potently stimulates cyclic GMP production in rat cultured vascular smooth muscle cells. Biochem. Biophys. Res. Commun. 170(1):201-208.

29. Furuya, M., N. Ohnuma, M. Takehisa, Y. Hayasi, T. Ishihara, N. Minamino, K. Kangawa, and H. Matsuo. 1991. Pharmacological activities of brain natriuretic peptides of human porcine and rat origin. Eur. J. Pharmacol. 200:233237.

30. Khurana, M. L., and K. N. Pandey. 1993. Receptor-mediated stimulatory effect of atrial natriuretic factor, brain natriuretic peptide, and C-type natriuretic peptide on testosterone production in purified mouse leydig cells: activation of cholesterol side-chain cleavage enzyme. Endocrinology. 133(5):2141-2149. 